\begin{tabular}{|c|l|}
\hline Title & Synthesis of Tetra ortho-Substituted Biaryls U sing A ry Itriolborates \\
\hline Author(s) & Li, Gao-Q_iang; Y amamoto, Y asunori; Miyaura, Norio \\
\hline Citation & $\begin{array}{l}\text { Synlett, 2011(12), 1769-1773 } \\
\text { https://doi.org/10.1055/s0030-1260932 }\end{array}$ \\
\hline Issue Date & 2011-07 \\
\hline Doc URL & http://hdl.handle.net/2115/49491 \\
\hline Rights & ○ 2011 Georg Thieme V erlag \\
\hline Type & article (author version) \\
\hline File Information & Syn2011-12_1769-1773.pdf \\
\hline
\end{tabular}

Instructions for use 


\title{
Synthesis of Tetra-ortho-substituted Biaryls using Aryltriolborates
}

\author{
Gao-Qiang Li, Yasunori Yamamoto* and Norio Miyaura \\ Division of Chemical Process Engineering, Graduate School of Engineering, Hokkaido University, Sapporo 060-8628, Japan \\ Fax: +81-11-706-6560 \\ E-mail: yasuyama@eng.hokudai.ac.jp \\ Received: The date will be inserted once the manuscript is accepted.
}

\begin{abstract}
Tetra-ortho-substituted biaryls were synthesized by cross-coupling between 2,6-disubstituted bromoarenes and aryltriolborates possessing substituents at ortho-carbon. The use of a copper(I) halide such as $\mathrm{CuCl}$ (20 mol\%) with a palladium catalyst was found to be highly effective to give such sterically hindered biaryls in good yields.
\end{abstract}

Key words: cross-coupling, palladium catalyst, aryltriolborates, tetra ortho-substituted biaryls

Transition-metal-catalyzed cross-coupling reactions are effective synthetic methods for the formation of CC bonds. ${ }^{1}$ Cross-coupling reaction between arylmetal compounds and aryl electrophiles is a recent variant of traditional Ullman coupling for the synthesis of biaryls. Although this protocol has been extensively studied using a variety of organometallic reagents and electrophiles, ${ }^{1}$ interest has recently been shown in the use of nonmetallic boron compounds because of their high stability in air and water and compatibility with a broad range of functional groups. Tetra-orthosubstituted biaryls are important fragments of organic functional materials ${ }^{2}$ and many biologically active compounds such as michellamine and steganone. ${ }^{3} \mathrm{~A}$ recent advance is the use of electron-rich and sterically demanding ligands, such as tri-tertbutylphosphine, ${ }^{4} \quad$ dialkylarylphosphines, ${ }^{5-9} \mathrm{~N}$ heterocyclic carbenes, ${ }^{10-12}$ and other ligands, ${ }^{13-14}$ for synthesis of sterically hindered biaryl compounds. However, the use of large amounts of a base, especially a strong base, may be a major limitation for these applications. The development of an efficient, mild and operationally simple catalyst system avoiding the use of large amounts of a base remains a challenge and has becomes an urgent issue.

We recently reported that aryltriolborates, which have air- and water-stability and high solubility in organic solvents, undergo very smooth transmetalation to various transition metal complexes. The utility of these tetra-coordinated arylboron compounds was demonstrated in palladium-catalyzed cross-coupling, ${ }^{15}$ copper-catalyzed $N$-arylation of amines ${ }^{16}$ and rhodium-catalyzed 1,4-addition to enones. ${ }^{17}$

The reaction under aqueous conditions gives undesirable results due to competitive hydrolytic B-C bond cleavage. Such cleavage is accelerated by orthosubstituents and significantly accelerated by adjacent heteroatoms in the boronic acid derivative. ${ }^{18} 2$ Pyridylboronic acid does not give coupling products because of its very raid protodeboronation. ${ }^{19}$ High performance of 2-pyridine triolborates for metalcatalyzed bond-forming reactions was demonstrated in palladium- and copper-catalyzed cross-coupling reactions. ${ }^{15 b-c, ~ 16, ~} 17$ Herein, we report a novel approach for synthesis of tri- or tetra-ortho-substituted biaryls using ortho-substituted aryltriolborates.

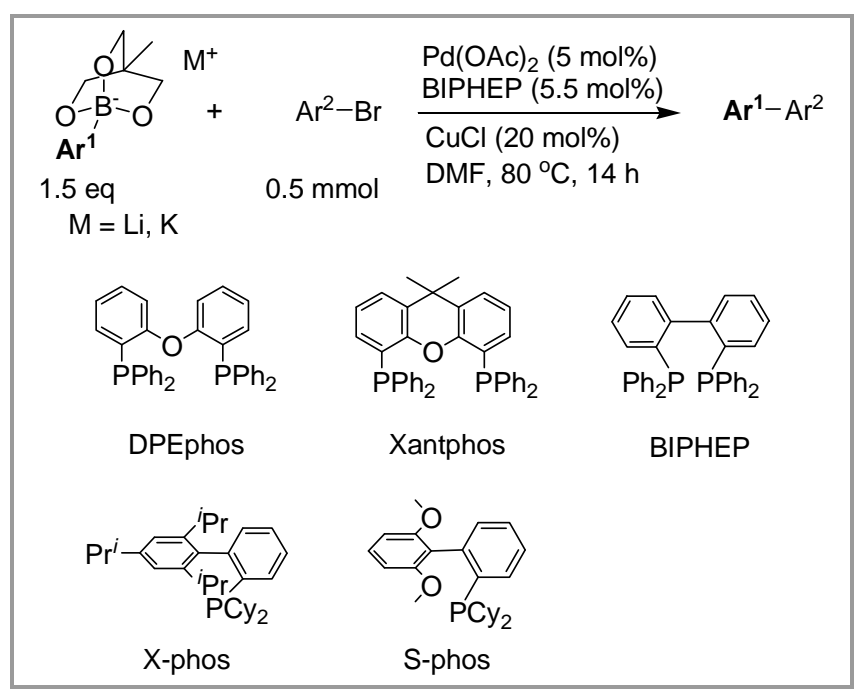

Scheme 1 Synthesis of Tetra-ortho-substituted Biaryls using Aryltriolborates

The synthesis of cyclic triolborates has been reported in our previous work. ${ }^{15}$ By using the same procedure, we successfully synthesized ortho-substituted triolborates $7, \mathbf{8}$ and $\mathbf{9}$ by treatment of hindered arylboronic acids with 1,1,1-tris(hydroxymethyl) ethane, producing ester intermediates that were further easily converted into aryltriolborates at the work of potassium hydroxide (Scheme 2). 3-Methyl-2pyridyltriolborate (11) was synthesized by arylation of $\mathrm{B}\left(\mathrm{O}^{\mathrm{i}} \mathrm{Pr}\right)_{3}$ with aryllithiums followed by ester exchange with triol (Scheme 3). This protocol afforded high yields for 2-pyridylboronates sensitive to B-C bond cleavage with water.

\begin{tabular}{|c|c|c|c|c|}
\hline $\mathrm{Ar}-\mathrm{B}(\mathrm{OH})_{2}$ & $\underset{-2 \mathrm{H}_{2} \mathrm{O}}{\stackrel{\mathrm{HO}}{\longrightarrow}}$ & & $\underset{-\mathrm{H}_{2} \mathrm{O}}{\stackrel{\mathrm{KOH}}{\longrightarrow}}$ & 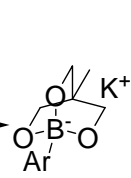 \\
\hline \multicolumn{2}{|c|}{$1\left(\mathrm{Ar}=2,6-\mathrm{Me}_{2} \mathrm{C}_{6} \mathrm{H}_{3^{-}}\right)$} & $4(99 \%)$ & & $7(82 \%)$ \\
\hline \multicolumn{2}{|c|}{$2\left(\mathrm{Ar}=2,4,6-\mathrm{Me}_{3} \mathrm{C}_{6} \mathrm{H}_{2}-\right)$} & $5(97 \%)$ & & $8(73 \%)$ \\
\hline \multicolumn{2}{|c|}{3 (Ar = 2-methl-1-naphthalenyl-) } & $6(99 \%)$ & & $9(87 \%)$ \\
\hline
\end{tabular}

Scheme 2 Synthesis of ortho-substituted aryltriolborates 


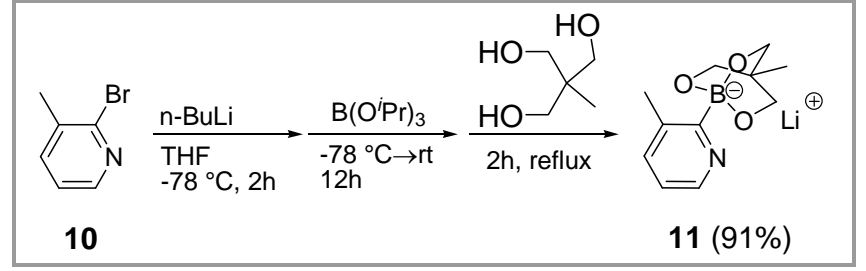

Scheme 3 Synthesis of 3-methyl-2-pyridyltriolborate

We chose 2, 6-dimethylphenyl triolborates (7) and 1bromo-2-methoxynapthalene to undergo coupling to optimize the reaction conditions (Table 1). Water proved to disfavor the sterically demanding coupling (entries1-4). To our delight, the $\mathrm{Pd}(\mathrm{OAc})_{2} / \mathrm{CuOAc}$ condition using $\mathrm{PPh}_{3}$ as a ligand gave $31 \%$ yield of the product (entry 5). Encouraged by this promising result, we further examined the efficiency of $\mathrm{CuI}^{15 \mathrm{~b}, \mathrm{c}}$, ${ }^{20}$ and $\mathrm{CuCl}^{21}$ in this hindered coupling reaction and $\mathrm{CuCl}$ gave the best yield, improving the yield to $64 \%$ (entry 7). When $\operatorname{Pd}(\mathrm{dba})_{2}$ was used in the same reaction, a decreased yield was observed (entry 8). Next we screened the solvent effects and no desired coupling product was observed in 1, 4-dioxane and $\mathrm{CH}_{3} \mathrm{CN}$, which may be caused by poor solubility for aryltriolborate in these solvents (entry 9). By examination of phosphine-based ligands, BIPHEP gave the best result, $84 \%$ yield (entry 14). By further investigations of the amounts of $\mathrm{Pd}(\mathrm{OAc})_{2}, \mathrm{CuCl}$ and BIPHEP, tetra-ortho-substituted biaryl was obtained finally in $95 \%$ yield using $5 \mathrm{~mol} \% \mathrm{Pd}(\mathrm{OAc})_{2} / 5.5$

Table 1 Optimization of tetra-ortho-substituted biaryls

\begin{tabular}{clllc}
\hline & & & \\
\hline
\end{tabular}

DMF as a solvent at $80{ }^{\circ} \mathrm{C}$ for $14 \mathrm{~h}$ (entry 16). No reaction was observed in the absence of $\mathrm{CuCl}$ (entry 19). There has not yet been a mechanistic study; however, such an effect of copper salts has been successfully utilized in analogous coupling reactions of 2-heteroaryl boron compounds. ${ }^{15 b-c, ~ 20,21}$ The role of copper salts seem to be facilitate the transmetalation of aryltriolborates to the arylpalladium bromides by the generation of arylcopper species. ${ }^{21}$

Under the optimized reaction conditions, hindered couplings occurred between aryltriolborates 7, 8, 9 and $\mathbf{1 1}$ and a number of hindered aryl bromides (Table 2). ${ }^{22}$ All of the ortho-substituted biaryls were obtained in excellent yields. 2-Bromo-3-methylthiophene was also evaluated in this hindered coupling. Orthosubstituted heterobiaryls were successfully formed in excellent yields using 1.2 equivalents of aryltriolborate (entries 6 and 15). 2, 6-Disubsituted aryltriolborate and hindered electron-deficient 1bromo-2-naphthaldehyde gave the desired biaryl in good yield using 2 equivalents of aryltriolborate (entry 12). To further demonstrate the efficiency of this protocol, some arenes with a base-sensitive functional group such as -COOR or -COR were also investigated and they smoothly yielded biaryls (entries 7 and 8). Heteroaromatic boronic acids often fail to give biaryls due to the high sensitivity of the B-C bond of electron-deficient heteroaryl rings to hydrolytic B-C bond cleavage with water. $^{15,23} 3$ Methyl-2-pyridylboronic acid is a typical example that undergoes very rapid cleavage with water. Crosscoupling reaction of 3-methyl-2-pyridyltriolborate (11) with 1-bromo-2-methoxynaphthalene or 4bromo-1,3,5-trimethyl-1H-pyrazole gave corresponding biaryls in high yields (entries 23 and 24).

In summary, we have described a novel and efficient catalyst system for the synthesis of tetra-orthosubstituted biaryls using aryltriolborates. Since the use of a base is avoided, a variety of functional groups may be accommodated in this reaction system.

Supporting Information for this article is available online at http://www.thieme-connect.de/ejournals/toc/synlett.

\section{Acknowledgment}

This work was supported in part by the Global COE Program (Project No. B01, Catalysis as the Basis for Innovation in Materials Science) from the Ministry of Education, Culture, Sports, Science, and Technology, Japan.

\section{References}

(1) For reviews, see: (a) Miyaura, N.; Suzuki, A. Chem. Rev. 1995, 95, 2457-2483. (b) Suzuki, A. in MetalCatalyzed Cross-Coupling Reactions ed. by Diederich, F.; and Stang, P. J. 'Wiley-VCH, Weinheim, 1998; p. 4998. (c) Miyaura, N. in Advances in Metal-Organic 
Table $2 \quad$ Hindered coupling between aryltriolborates and aryl bromides ${ }^{\mathrm{a}}$

\begin{tabular}{|c|c|c|c|c|c|c|c|}
\hline entry & $\mathrm{Ar}^{1}-\mathrm{Ar}^{2}$ & & yield $/ \%{ }^{b}$ & entry & $A r^{1}-\mathrm{Ar}^{2}$ & & yield $/ \%^{\mathrm{b}}$ \\
\hline 1 & & (13) & 95 & 13 & & (25) & 84 \\
\hline 2 & & (14) & 88 & 14 & & (26) & 99 \\
\hline 3 & & (15) & 83 & $15^{c}$ & & (27) & 83 \\
\hline 4 & & (16) & 81 & 16 & & (28) & 86 \\
\hline 5 & & (17) & 99 & 17 & & (29) & 97 \\
\hline $6^{\mathrm{c}}$ & & (18) & 90 & 18 & & (30) & 82 \\
\hline $7^{c}$ & & (19) & 97 & 19 & & (31) & 78 \\
\hline $8^{c}$ & & (20) & 99 & 20 & & (14) & 84 \\
\hline 9 & & (21) & 92 & 21 & & (22) & 91 \\
\hline 10 & & (22) & 90 & $22^{c}$ & & (32) & 80 \\
\hline 11 & & (23) & 87 & $23^{\mathrm{d}}$ & & (33) & 88 \\
\hline $12^{\mathrm{d}}$ & & (24) & 82 & $24^{\mathrm{d}}$ & & (34) & 90 \\
\hline
\end{tabular}

${ }^{a}$ A mixture of $\mathrm{Ar}^{1} \mathrm{~B}\left(\mathrm{OCH}_{2}\right)_{3} \mathrm{CCH}_{3}(0.75 \mathrm{mmol}), \mathrm{Ar}^{2} \mathrm{Br}(0.5 \mathrm{mmol}), \mathrm{Pd}(\mathrm{OAc})_{2}(5 \mathrm{~mol} \%)$, BIPHEP (Pd : P = $\left.1: 1.1\right)$ and $\mathrm{CuCl}(0.1$ mmol) in anhydrous DMF was stirred at $80{ }^{\circ} \mathrm{C}$ for $14 \mathrm{~h} .{ }^{b}$ Isolated yields by chromatography. ${ }^{c} 1.2$ eq aryltriolborate was used. ${ }^{d} 2.0$ eq aryltriolborate was used. 
Chemistry, ed. by Liebeskind, L. S. 'JAI Press, Stamford, 1998, Vol. 6, p. 187. (d) Miyaura, N. in Topics in Current Chemistry, 2002, 219, p. 11. (e) Suzuki A. and Brown, H. C. Organic Synthesis via Boranes Vol. 3 Suzuki Coupling, Aldrich Chemical Co., Milwaukee, 2003. (f) Miyaura, N. in Metal-Catalyzed CrossCoupling Reactions, Second, Completely Revised and Enlarged Edition, ed. by de Meijere A.; Diederich, F. Wiley-VCH, 2005, p. 41-124.

(2) (a) Hassan, J.; Svignon, M.; Gozzi, C.; Schulz, E.; Lemaire, M. Chem. Rev. 2002, 102, 1359-1469. (b) Bringmann, G.; Gulder, T.; Gulder, T. A. M.; Breuning, M. Chem. Rev. 2011, 111, 563-639.

(3) (a) Upender, V.; Pollart, D. J.; Liu, J.; Hobbs, P. D.; Olsen, C.; Chao, W.-R.; Bowden, B.; Crase, J. L.; Thomas, D. W.; Pandey, A.; Lawson, J. A.; Dawson, M. I. J. Heterocyclic Chem. 1996, 33, 1371-1384. (b) Hoye, T. R.; Chen, M. J. Org. Chem. 1996, 61, 7940-7942. (c) Monovich, L. G.; Huérou, Y. L.; Rönn, M.; Molander, G. A. J. Am. Chem. Soc. 2000, 122, 52-57.

(4) (a) Dai, C.; Fu, G. C. J. Am. Chem. Soc. 2001, 123, 2719-2724. (b) Littke, A. F.; Schwarz, L.; Fu, G. C. J. Am. Chem. Soc. 2002, 124, 6343-6348.

(5) (a) Yin, J.; Rainka, M. P.; Zhang, X. X.; Buchwald, S. L. J. Am. Chem. Soc. 2002, 124, 1162-1163. (b) Walker, S. D.; Barder, T. E.; Martinelli, J. R.; Buchwald, S. L. Angew. Chem. Int. Ed. 2004, 43, 1871-1876. (c) Milne, J. E.; Buchwald, S. L. J. Am. Chem. Soc. 2004, 126, 13028-13032. (d) Barder, T. E.; Walker, S. D.; Martinelli, J. R.; Buchwald, S. L. J. Am. Chem. Soc. 2005, 127, 4685-4696.

(6) (a) Hoshi, T.; Nakazawa, T.; Saitoh, I.; Mori, A.; Suzuki, T.; Sakai, J.; Hagiwara, H. Org. Lett. 2008, 10, 20632066. (b) Hoshi, T.; Saitoh, I.; Nakazawa, T.; Suzuki, T.; Sakai, J.; Hagiwara. H. J. Org. Chem. 2009, 74, 40134016.

(7) Tang, W.; Capacci, A. D.; Wei, X.; Ki, W.; White, A.; Patel, N. D.; Savoie, J.; Gao, J. J.; Rodriguez, S.; Qu, B.; Haddad, N.; Lu, B. Z.; Krishnamurthy, D.; Yee, N. K.; Senanayake, C. H. Angew. Chem. Int. Ed. 2010, 49, 5879-5883.

(8) So, C. M.; Chow, W. K.; Choy, P. Y.; Lau, C. P.; Kwong, F. Y. Chem. Eur. J. 2010, 16, 7996-8001.

(9) To, S. C; Kwong, F. Y. Chem. Commun. 2011, DOI:10.1039/c1cc10708a

(10) Altenhoff, G.; Goddard, R.; Lehmann, C. W.; Glorius, F. J. Am. Chem. Soc. 2004, 126, 15195-15201.

(11) Song, C.; Ma, Y.; Chai, Q.; Ma, C.; Jiang, W.; Adrus, M. B. Tetrahedron 2005, 61, 7438-7446.

(12) Organ, M. G.; Çalimsiz, S.; Sayah, M.; Hoi, K. H.; Lough, A. J. Angew. Chem. Int. Ed. 2009, 48, 2383-2387.

(13) Ackermann, L.; Potukuchi, H. K.; Althammer, A.; Borm, R.; Mayer, P. Org. Lett. 2010, 12, 1004-1007.

(14) Lee, D.-H.; Jin, M.-J. Org. Lett. 2011, 13, 252-255.

(15) (a) Yamamoto, Y.; Takizawa, M.; Yu, X.-Q.; Miyaura, N. Angew. Chem. Int. Ed. 2008, 47, 928-931. (b) Yamamoto, Y.; Takizawa, M.; Yu, X.-Q.; Miyaura. N. Heterocycles, 2010, 80, 359-368. (c) Yamamoto, Y.; Sugai, J.; Takizawa, M.; Miyaura, N. Org. Synth. 2011, 88, 79-86.

(16) Yu, X.-Q.; Yamamoto, Y.; Miyaura. N. Chem. Asian J. 2008, 3, 1517-1522.

(17) (a) Yu, X.-Q.; Yamamoto, Y.; Miyaura. N. Synlett 2009, 994-998. (b) Yu, X.-Q.; Shirai, T.; Yamamoto, Y.; Miyaura. N. Chem. Asian J. 2011, 6, 932-937.

(18) (a) Kuvila, H. G.; Reuwer,J. F.; Mangravite, J. A. J. Am. Chem. Soc. 1964, 86, 2666-2670. (b) Brown, R. D.; Buchanan, A. S.; Humffray, A. A. Aust. J. Chem. 1965, 18, 1521.
(19) Tyrrell, E.; Brookes, P. Synthesis 2003, 469. (b) Molander, G. A.; Biolato, B. J. Org. Chem. 2003, 68, 4302. (c) Campeau, L.-C.; Fagnou, K. Chem. Soc. Rev. 2007, 36, 1058.

(20) (a) Hodgson, P. B.; Salingue, F. H. Tetrahedron Lett. 2004, 45, 685-687. (b) Gros, P.; Doudouh, A.; Fort, Y. Tetrahedron Lett. 2004, 45, 6239-6241. (c) Jones, N. A.; Antoon, J. W.; Browie, Jr., A. L.; Borak, J. B.; Stevens, E. P. J. Heterocycl. Chem. 2007, 44, 363-367. (d) Gütz, C.; Lützen, A. Synthesis 2010, 85-90.

(21) Deng, J. Z.; Paone, D. V.; Ginnetti, A. T.; Kurihara, H.; Dreher, S. D.; Weissman, S. A.; Stauffer, S. R.; Burgey, C. S. Org. Lett. 2009, 11, 345-347.

(22) General procedure for synthesis of ortho-substituted biaryls

The aryl bromide $(0.5 \mathrm{mmol})$, aryl triolborate $(0.75$ mmol), palladium acetate (5 mol \%), BIPHEP (5.5 mol \%), $\mathrm{CuCl}(0.1 \mathrm{mmol})$ were placed in a flash under nitrogen atmosphere. dry DMF (5 mL) was added. The mixture was stirred at $80{ }^{\circ} \mathrm{C}$ for $14 \mathrm{~h}$. After cooling to room temperature, the crude mixture was filtered through a plug of Celite and washed with ether. The filtrate was then concentrated in vacuo to afford the crude product, which was further purified by chromatography on silica gel with hexanes/EtOAc (99:1-10:1).

(23) Tyrrell, E.; Brookes, P. Synthesis 2003, 469-483. 


\section{Synthesis of Tetra-ortho-substituted Biaryls using Aryl Triolborates}

We have demonstrated the efficiency of aryl triolborates possessing substituents at ortho-carbon for synthesis of tetraortho-substituted biaryls by cross-coupling with 2,6-disubstituted bromoarenes. The use of $\mathrm{CuCl}(20 \mathrm{~mol} \%)$ with a palladium catalyst was found to be highly effective to give such sterically hindered biaryls in good yields. Since the use of a base is avoided, a variety of functional groups may be accommodated in this reaction system.

Short title: synthesis of ortho-substituted biaryls

\section{Graphical abstract:}

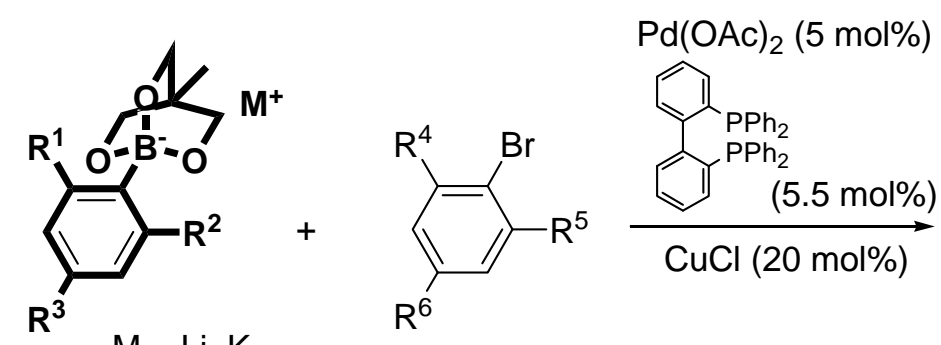

$M=L i, K$
$\mathrm{Pd}(\mathrm{OAc})_{2}(5 \mathrm{~mol} \%)$<smiles>[R]c1cc([R])c(-c2c([R])cc([R3])cc2[R])c([R])c1</smiles>

$78-99 \%$<smiles>Cc1cccc(C)c1[B-]12OCC(C)(CO1)C2[TeH]</smiles><smiles>Cc1cc(C)c([B-]23CCC(CO2)O3)c(C)c1</smiles><smiles>Cc1ccc2ccccc2c1[B-]12[CH+]C(C)(CO1)CO2</smiles><smiles></smiles>

Dr. Yasunori Yamamoto

Division of Chemical Process Engineering,

Graduate School of Engineering,

Hokkaido University,

kita 13, nishi 8, kita-ku

Sapporo 060-8628, Japan

TEL\&FAX: +81 117066561

Mail: yasuyama@eng.hokudai.ac.jp 